\title{
Stigmatic Receptivity Limits the Effective Pollination Period in 'Agua de Aranjuez' Pear
}

\author{
Javier Sanzol, ${ }^{1}$ Pilar Rallo, ${ }^{2}$ and María Herrero ${ }^{3}$ \\ Unidad de Fruticultura, SIA-DGA, Campus de Aula Dei, 50080 Zaragoza, Spain
}

\begin{abstract}
AdDITIONAL INDEX wORDS. Pyrus communis, pear, effective pollination period, stigmatic receptivity
ABstract. Apples and pears are fruit crops particularly susceptible to cropping irregularities. A strong relationship has been observed between the effective pollination period (EPP) and the general cropping of the orchard. The EPP concept has also been proven to be a useful parameter to establish a relationship between the variation in the reproductive process and cropping behaviors. For apples and pears, a slow pollen tube growth has been shown to be the main limiting factor of the EPP in the traditional cooler temperate cultivation regions. However, while higher temperatures speed up the pollen tube growth, the expansion of these crops into warmer areas often results in failures of fruit set. Thus, with the aim to ascertain the main limiting factor responsible for fruit set failures in Mediterranean conditions we have evaluated the EPP for two consecutive years in 'Agua de Aranjuez' pear, the main Spanish cultivar, by studying the stigmatic receptivity, pollen tube kinetics, and ovule development. Complete flower fertility was maintained for just 2 days after anthesis in both years. Pollen tube kinetics and ovule degeneration do not appear to limit flower receptivity. However, the stigmatic receptivity expressed as flowers with at least one receptive stigma, closely matches the duration of the EPP evaluated from fruit set experiments. This was consistent over the 2 years of experiments, in spite of the differences recorded in the EPP, suggesting that stigmatic receptivity is clearly the limiting factor of flower receptivity. This is the first report for stigmatic receptivity limiting the EPP in pears and suggests that stigmatic receptivity could be an important factor limiting pear flower receptivity and hence cropping performance under warmer conditions.
\end{abstract}

Apples and pears are fruit crops particularly susceptible to cropping irregularity (Atkinson and Taylor, 1994; Beattie and Folley, 1977; Browning and Miller, 1992; Jackson and Hamer, 1980). Analyzing fruit set determinants in apple, Williams (1970) could demonstrate a strong relationship between the effectiveness of flowers to set fruit following delayed pollinations and general orchard performance suggesting that cropping variability among different sites could therefore be explained in terms of differences in flower receptivity.

To assess flower receptivity, Williams (1965) introduced the effective pollination period (EPP) concept that is defined as the time during which the flower is able to set a fruit, provided that pollination is not limited. The approach followed to estimate the EPP in orchard conditions consists in hand-pollinating flowers at time intervals from anthesis, and recording the initial and final fruit set in those flowers (Williams, 1970b). The EPP can also be expressed as an equation that correlates the processes that operate during the reproductive phase. In this way, the EPP is defined as the longevity of the ovules minus the time lag between pollination and fertilization, assuming that this value does not exceed the receptive period of the stigmas (Williams, 1966).

Variation in EPP values has been claimed to be due both to environmental effects, mainly temperature (Tromp and Borsboom, 1994; Vasilakakis and Porlingis, 1985), and to flower internal causes, which have been termed flower quality (Ferree and Rom, 1984; Williams, 1965). The relative influence of each of those two factors on the reproductive process evaluated through stigmatic receptivity, pollen tube kinetics and ovule development, finally determines the length of flower receptivity.

Reveived for publication Accepted for publication 6 Apr. 2003. We thank I. Hormaza and J.Rodrigo for critical reading and helpful comments on the manuscript. JS was supported by an INIA and a SIA fellowship, and financial support for this work was also provided by INIA (Project grant SC98-049).

To whom reprint requests should be addressed; e-mail jsanzol@aragob.es.

${ }^{2}$ Current address: Departamento de Agroforestería, EUITA, Carretera de Utrera Km 1, 4113 Sevilla, Spain.

${ }^{2}$ Current address: Departamento de Pomología, EE. de Aula Dei-CSIC, Campus de Aula Dei, Apartado 202, 50080 Zaragoza, Spain.
Since the EPP concept was proposed several experiments have been conducted to evaluate it in different fruit tree species. A review of these experiments (Sanzol and Herrero, 2001) shows that EPP values are highly variable among species, cultivars, years and sites, and that EPP values per se do not have a special relevance. However, this variability has proven to be most useful when it is analyzed in relation to the different processes that determine the EPP. Indeed, in different species a good correspondence has been obtained between the values of flower receptivity, from trials of fruit set following delayed pollinations, and those coming from microscopic studies of stigmatic receptivity, pollen tube kinetics, and ovule development (reviewed in Sanzol and Herrero, 2001).

Apples and pears are the most important fruit crops in the cooler temperate regions (Watkins, 1976). Under the prevailing cold springs in these areas, a slow pollen tube growth is the main limiting factor of the EPP for these species. However, while warmer temperatures speed up the pollen tube growth, the expansion of these crops into warmer areas often results in failures of fruit set.

'Agua de Aranjuez', the main pear cultivar grown in Spain, appears to be well adapted to relatively warm environments. It has lower chilling requirements as compared to those usually displayed by the main pear cultivars and can be cultivated in environments that are outside the normal climatic range for pears, such as some locations in the Mediterranean basin (Tabuenca, 1964). However, under the prevailing growing conditions in those areas it is a cultivar particularly prone to erratic fruit set (Cambra and Herrero, 1978; Herrero, 1983).

With the aim to ascertain the main limiting factor responsible for fruit set failures in these Mediterranean conditions we have evaluated the EPP for two consecutive years in 'Agua de Aranjuez' pear. In parallel, a study of the stigmatic receptivity, pollen tube kinetics and ovule development was carried out.

\section{Materials and Methods}

Plant material. Six 18-year-old 'Agua de Aranjuez,' pear trees grafted on 'EM' quince rootstock and grown under standard 
cultural conditions, were used for this work. The same six trees were usedfor all of the experiments. Trees were placed in an experimental orchard located in the Campus de Aula Dei in Zaragoza, Spain. This area is representative of the typical growing environmental conditions for this cultivar.

Pollination procedures. Compatible pollen from 'Castell' (Sanzol and Herrero, 2002a) was collected from flowers at the balloon stage by removing the anthers and leaving them to dry at room temperature on a piece of paper. Pollen was sieved $48 \mathrm{~h}$ later with a $0.26-\mathrm{mm}$ mesh and stored at $4{ }^{\circ} \mathrm{C}$ until used. To prevent free pollination (Free, 1964), flowers were emasculated at balloon stage, $48 \mathrm{~h}$ before anthesis, by removing the petals and anthers with the help of tweezers.

EFfective POllination PERIOD ESTIMATION. To ascertain the EPP, the orchard procedure described by Williams (1970b) for apple was followed. Six trees randomly selected in the orchard were used. Eight clusters (inflorescences) per day of pollination were randomly selected in each tree. For each cluster only three flowers at the balloon stage were left. These flowers were emasculated and hand-pollinated $0,2,4,6,8$, and $10 \mathrm{~d}$ after anthesis. Fruit set was recorded $28 \mathrm{~d}$ after pollination for initial fruit set, after 'June Drop', and at fruit maturity for final fruit set. Fruit were harvested and weighed and seed set per fruit was recorded. Data were analyzed using analysis of variance and Duncan's multiple range tests.

STIGMATIC RECEPTIVITY. To ascertain the stigmatic receptivity, the same experimental design as for the estimation of the EPP, was followed. The same six trees were used, but a different batch of clusters was used for this experiment. Flowers were emasculated $48 \mathrm{~h}$ before anthesis and pollinated $0,2,4,6,8$, and $10 \mathrm{~d}$ after anthesis. For each pollinating day, 10 flowers taken randomly from the six trees,were removed $24 \mathrm{~h}$ after pollination and fixed in FAA (formalin-acetic acid-ethanol 70\%) (1:1:18) (Johansen, 1940). Following fixation, pistils were washed with distilled water, three times, for $1 \mathrm{~h}$ each wash, and left overnight in 5\% sodium sulfite. On the following day, they were autoclaved in 5\% sodium sulfite for $10 \mathrm{~min}$ at $1 \mathrm{~kg} \cdot \mathrm{cm}^{-2}$ (Jefferies and Belcher, 1974) and mounted in squash preparations with $0.1 \%$ aniline blue in $0.1 \mathrm{~N}$ $\mathrm{K}_{3} \mathrm{PO}_{4}$ (Linskens and Esser, 1957). Preparations were viewed under an Ortholux II microscope with UV epifluorescence using a BP 355-425 exciter filter and an LP 460 barrier filter. A stigma was considered to be receptive when it was able to give support for pollen hydration, germination, and initial pollen tube growth into the transmitting tissue of the style (Sanzol et al., 2003a). Records of stigmatic receptivity were expressed as the percentage of receptive stigmas in a population of 50 stigmas. Correlations were determined by means of the Pearson correlation test.

Pollen tube growth and ovule Development. To monitor pollen tube kinetics and ovule development, two groups of flowers were established. In each group, 16 clusters with three flowers in each cluster were randomly selected in two out of the six trees used in the previous experiments. This gave a total of 288 flowers per treatment. Flowers were emasculated $48 \mathrm{~h}$ before anthesis. One of the groups of flowers was hand-pollinated at anthesis. Flowers in the second group were left unpollinated. Following anthesis-pollination, 10 flowers were sampled per day and treatmentduring $28 \mathrm{~d}$ after anthesis and fixed in FAA, giving a total of 560 flowers. Following fixation, to evaluate pollen tube growth in the style, pistils were prepared and viewed as described above for stigmatic receptivity. To study pollen tube growth in the ovary and ovule development, ovaries were embedded in paraffin wax, after dehydration in tertiary butyl alcohol series $(50 \%, 70 \%, 85 \%, 95 \%$, and $100 \%)$. Ten-micrometer sections were mounted and dewaxed with xylene, rehydrated, left to dry, and stained with $0.1 \%$ aniline blue in $0.1 \mathrm{~N} \mathrm{~K}_{3} \mathrm{PO}_{4}$ (Linskens and Esser, 1957). Fixed flower were microscopically examined until pollen tubes reached the ovules and fertilization had occurred.

\section{Results}

Fruit AND SEED SET. Fruit set records were higher the first than the second year. However, there were not significant differences between maximum initial fruit set values recorded in both years for the first $2 \mathrm{~d}$ of pollination following anthesis (Fig. 1). The higherst initial fruit set was recorded for flowers pollinated at anthesis and $2 \mathrm{~d}$ after anthesis. Four days after anthesis initial fruit set was significantly reduced for both years of experiments. Final fruit set declined progressively in the first year, but this reduction was more drastic in the second year of experiment (Fig. 1).

While differences between years were recorded for fruit size, not significant differences in fruit size were apparent among days of pollination (Fig. 2). On the other hand, seed set was maximum the first year, on fruits from flowers pollinated at anthesis and $2 \mathrm{~d}$ after anthesis, and it declined progressively thereafter. In the second year, although the second day of pollination presents the highest record of seed set, differences between the other treatments were nott significant (Fig. 2). Finally, a low correlation was observed between number of seeds and fruit size $\left(r^{2}=0.23\right.$, for the first and $r^{2}=0.26$ for the second year of experiment, respectively).
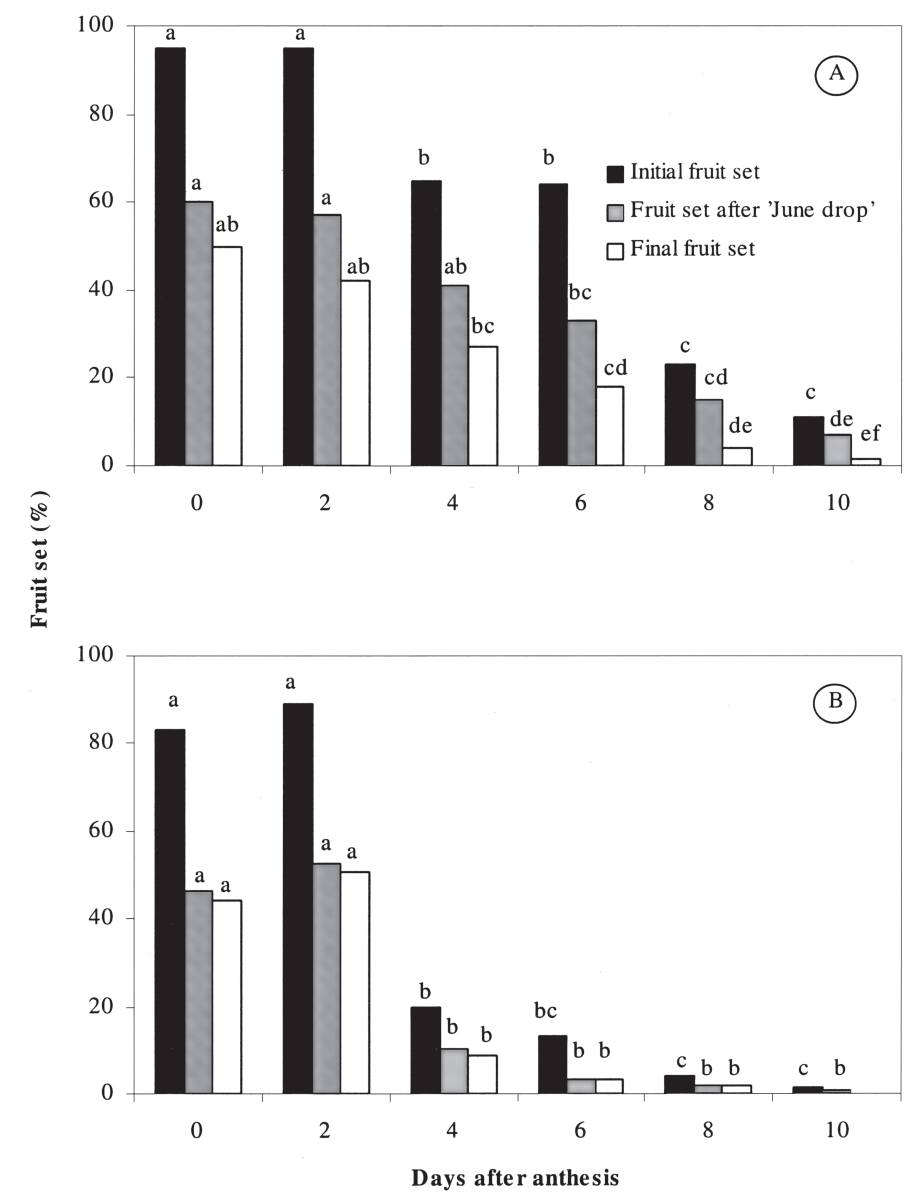

Fig.1. Fruit set values coming from delayed pollination the first $(\mathbf{A})$ and second (B) year of experiment. Flowers were pollinated 0, 2, 4, 6, 8, and $10 \mathrm{~d}$ after anthesis. Data were subjected to analysis of variance. Mean separation by Duncan's multiple range test, $p<0.05$. 
Pollen tube kinetics and ovule Development. Pollen tube kinetics and ovule development, were studied to ascertain the factors determining the EPP. In receptive stigmas, $24 \mathrm{~h}$ after pollination, pollen had already penetrated the transmitting tissue of the style. Four days after pollination, the first pollen tubes could be seen at the base of the style and one day later pollen tubes could be observed growing in the placenta of the ovary. The first fertilized ovules were recorded on day 7 for the first year of the experiment and on day 8 for the second. Maximum number of fertilized ovules was observed on the eighth and tenth day after pollination, in the first and second year of the experiment, respectively.

The main initial fruit drop occurred both years for flowers pollinated $4 \mathrm{~d}$ after anthesis or later. To determine if this fall in fruit set, was a consequence of early ovule degeneration, ovule development was analyzed at the time the pollen tubes were expected to reach the ovules in 4 -d-old pollinated flowers. Given that, the time lag between pollination and fertilization was $8 \mathrm{~d}$ for the first and $10 \mathrm{~d}$ for the second year of experiment, 12- and 14-d-old ovules from unpollinated flowers in the first and the second year of experiment, respectively, were observed with the microscope. Embryo sacs at these stages present a mature structure with two synergids and an egg cell with a prominent vacuole that fills almost all of the cellular space. The two polar nuclei have fused into a single nucleus with a prominent nucleolus. By the time of fertilization no signs
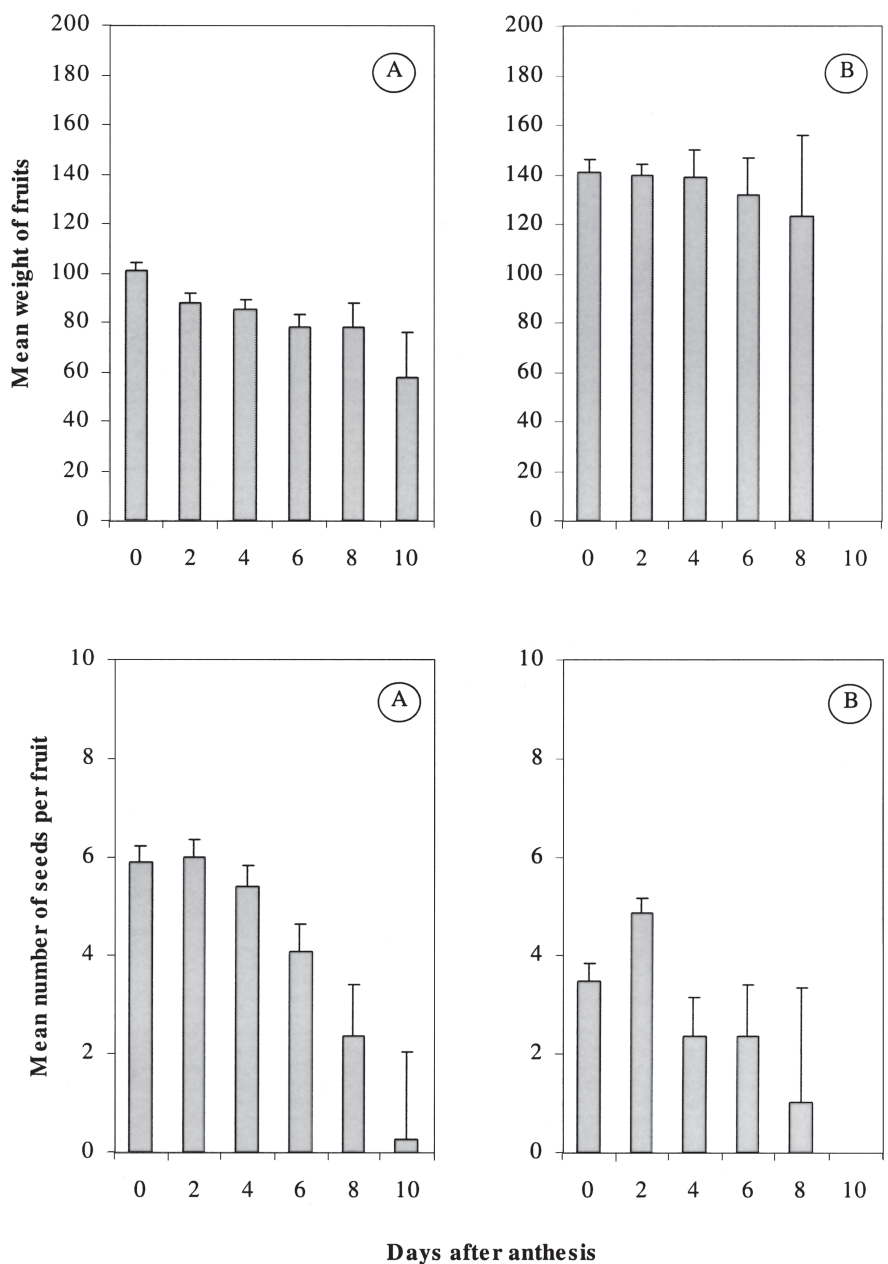

Fig. 2. Mean fruit weight and number of seeds per fruit obtained from flowers pollinated $0,2,4,6,8$, and $10 \mathrm{~d}$ after anthesis during the first $(\mathbf{A})$ and second (B) year of experiment. Mean separation by Duncan's multiple range test, $p<$ 0.05 after performance of analysis of variance. of ovule degeneration were observed.

Stigmatic Receptivity. Since pollen tube kinetics and ovule degeneration could not explain the reduction in fruit set, stigmatic receptivity was evaluated as the possible limiting factor of the EPP. Stigmatic receptivity was assessed as the capacity of the stigmas to offer support for pollen germination and initial pollen tube growth in the style. For both years, stigmatic receptivity for flowers pollinated at anthesis was lower than for flowers pollinated $2 \mathrm{~d}$ after anthesis (Fig. 3). In the first year of experiment, values were maintained around $60 \%$ for the first $6 \mathrm{~d}$ after anthesis and fell drastically the eighth day after anthesis. This pattern was quite different for the second year, in which the percentage of receptive stigmas sharply decreased by $4 \mathrm{~d}$ after anthesis (Fig. 3).

To evaluate the relevance of stigmatic receptivity limiting the EPP, the pattern of stigmatic receptivity was plotted against the pattern of fruit set. As just one fertilized ovule is required to induce ovary development and, hence, initial fruit set in this cultivar (Sanzol, 2001), initial fruit set was correlated with the percentage of flowers with at least one receptive stigma (Fig. 4). For the 2 years of experiments both processes followed the same pattern, presenting a high correlation; $r^{2}=0.92(\mathrm{n}=6 ; p=0 ., 0088)$ for the first and $r^{2}=0.99(\mathrm{n}=6 ; p=0.0001)$ for the second year. Interestingly, the correlation value improved in the first year when immature stigmas were also taken into account as potentially receptive stigmas $\left(r^{2}=\right.$ $0.97 ; \mathrm{n}=6 ; p=0.0013)$.

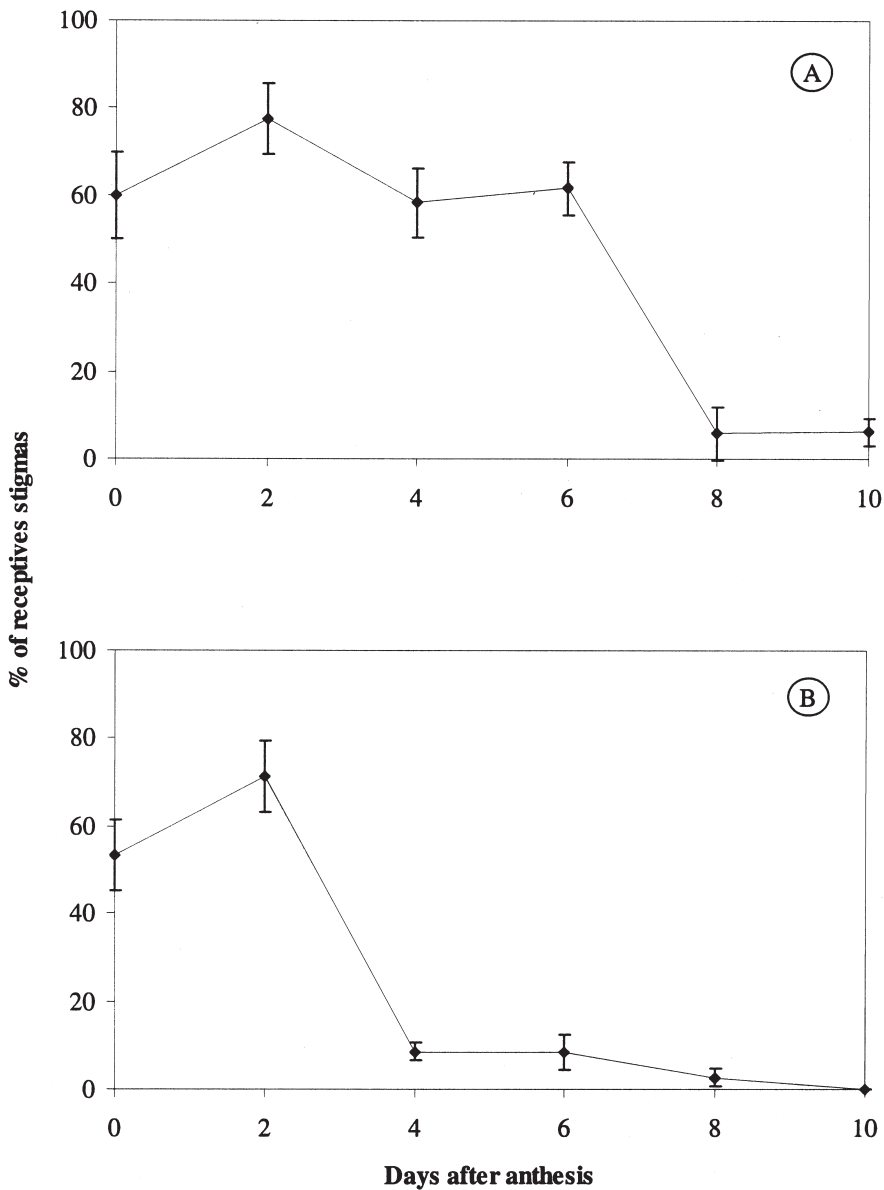

Fig. 3. Percentage of receptive stigmas for flowers pollinated $0,2,4,6,8$, and $10 \mathrm{~d}$ after anthesis the first (A) and second (B) year of experiment. Standard error $(\mathrm{SE})$ is represented by vertical bars. 


\section{Discussion}

'Agua de Aranjuez' has a short flower receptivity period as compared with other pear cultivars, which is manifested by a significant reduction in the initial fruit set when pollination occurs following $2 \mathrm{~d}$ after anthesis. In our conditions, stigmatic receptivity has been shown to operate as a clear limiting factor of the EPP.

The short flower receptivity period described in this work for 'Agua de Aranjuez' pear, appears to be a general characteristic of this cultivar, since a short duration of the EPP was also obtained in other trials (Herrero, 1983; Sotes, 1975). Those data contrast with EPP values obtained for other pear cultivars, which usually range between 6 and 11 days (Crisosto et al., 1992; Le Lézec et al., 1997; Tromp and Borsboom, 1994; Vasilakakis and Porlingis, 1985; Williams, 1966). Among the cultivars studied, just 'Doyenné du Comice' presents similar EPP values to those recorded here for 'Agua de Aranjuez' (Crisosto et al., 1992; Tromp and Borsboom, 1994; Williams, 1966). Interestingly, this cultivar also fails to crop properly (Jaumien, 1968; Williams, 1970c), and several abnormalities have been recorded in the embryo sac, which could be related to its poor cropping performance (Jaumien, 1968). In our study, no alterations in embryo sac development that could account for this reduction in fruit set have been observed. Likewise, the possibility that early ovule degeneration could play a role limiting the EPP cannot be sustained, since ovules of unpollinated flowers did not present any symptoms of degeneration at the time that flowers pollinated $4 \mathrm{~d}$ after anthesis, were fertilized. On the other hand, pollen tubes growth rates were similar to those previously described for

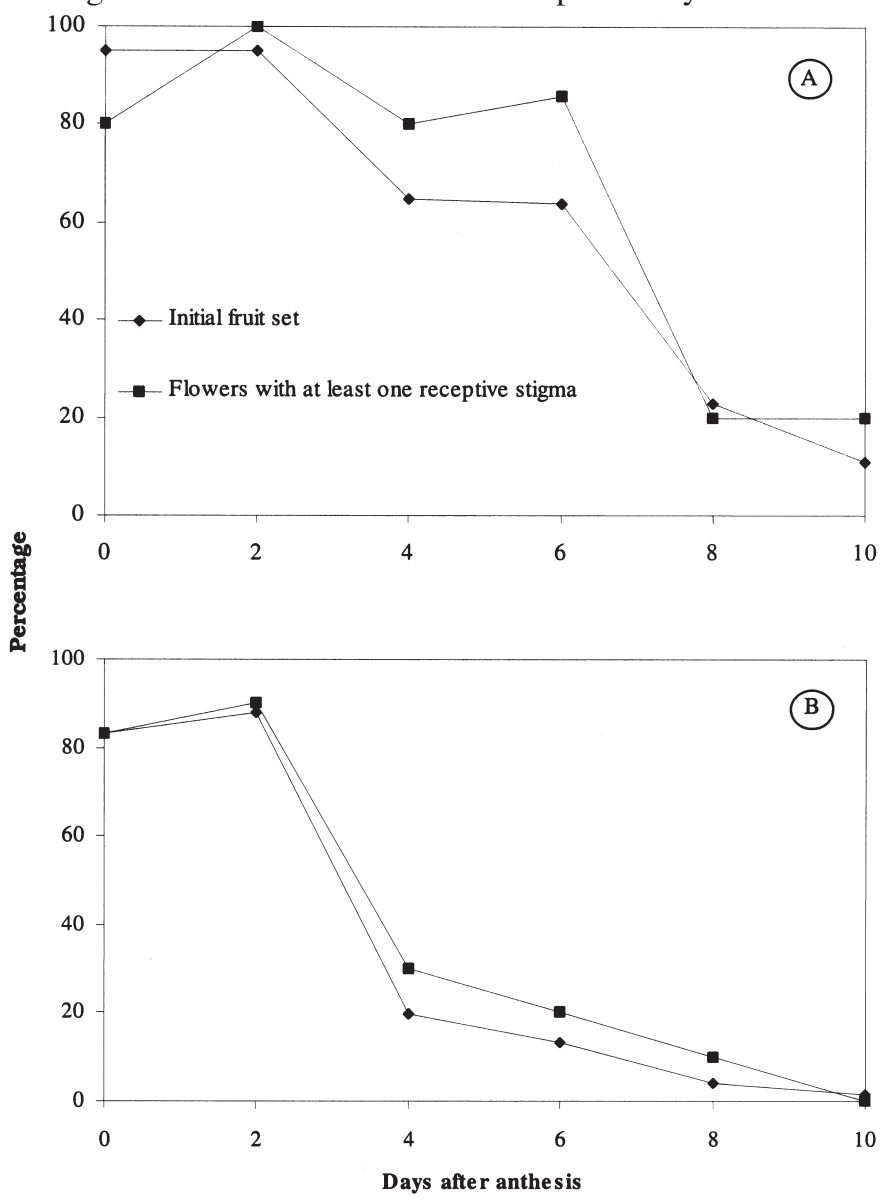

Fig. 4. Initial fruit set and percentage of flowers with at least one receptive stigma during the first (A) and second (B) year of experiment. $r^{2}$ Pearson correlation test. this species (Le Lezec et al., 1997; Lombard et al., 1972).

While a slow pollen tube growth or an early ovule degeneration do not appear to be responsible for this short EPP, the duration of stigmatic receptivity expressed as flowers with at least one receptive stigma, shows a clear fit with initial fruit set records. This was consistent over two years of experiments, despite the fact that different patterns were obtained between years. A similar situation has been described in kiwi (González, et al., 1995) where stigmatic receptivity and fruit set are closely correlated. In apricots (Egea and Burgos, 1992), a short EPP has been related to a decrease in the number of germinated pollen grains.

In this pear cultivar, not all the stigmas are receptive at anthesis (Herrero, 1983, Sanzol et al, 2003a). This could be a generalized phenomenon in pear since it has been reported for other cultivars (Modlibowska, 1945). Our results show how the best correlation is obtained between initial fruit set and the percentage of flowers with at least one receptive stigma. The correlation value was slightly lower the first year of experiment $\left(r^{2}=0.92\right)$ than the second $\left(r^{2}\right.$ $=0.99$ ). However, when immature stigmas are also included as potentially receptive stigmas, this fit increases substantially $\left(r^{2}=\right.$ 0.97), indicating that immature stigmas should also be taken into account when stigmatic receptivity is assessed as a limiting factor of the EPP in pear.

It is interesting to emphasize that the best correlations where obtained when stigmatic receptivity was expressed as flowers with at least one receptive stigma. This stresses the fact that for a flower to be functional a single receptive stigma appears to be sufficient. Consistent with this result is the observation that in this cultivar, while not having a parthenocarpic tendency, just one fertilized ovule is required to establish initial fruit set (Sanzol, 2001).

The close correlation between stigmatic receptivity and fruit set, together with the fact that the time of stigmatic receptivity is rather short, may explain the fruit set problems recorded in this cultivar (Cambra and Herrero, 1978). In addition, this cultivar has proven to be self-incompatible (Sanzol and Herrero, 2002b) and has an early flowering, with few pear cultivars overlapping its flowering period. Results herein suggests methods to improve pear production, and lead us to explore the possibilities of an adequate production following adequate pollination. A search for suitable pollinators has been conducted and currently there are several cultivars with a coincident flowering period, intercompatible and with a commercial interest (Sanzol et al., 2003b). Likewise the sustainability of this crop in field conditions under adequate pollination has been proven (Sanzol and Herrero, 2002b).

Temperature has been pointed out as one of the main factors interacting with flower receptivity, strongly determining either stigmatic receptivity, pollen tube growth or ovule development (reviewed by Sanzol and Herrero, 2001). Thus, under specific conditions, flower receptivity is expected to be the result of the relative influence of temperature over those parameters. Cool as compared to normal spring temperatures during flowering decrease pollen tube growth rate as well as delay ovule degeneration. Under those conditions a shortening of the EPP values occurs since the increase in ovule longevity usually does not outweighs the slower pollen tube growth rate (Tromp and Borsboom, 1994). It is well established in those situations that the EPP is determined by the longevity of the ovules minus the time lag between pollination and fertilization (Williams, 1965). As temperature increases pollen tube growth is accelerated and the EPP is expected to increase, as long as this temperature increase does not have a stronger deleterious effect on ovule longevity. This has been the case in several situations (Thompson and Liu, 1973; Vasilakakis and Porlingis, 1985). However, as Williams 
(1965) pointed out, ovule longevity minus the full time of pollen tube growth can exceed the period the stigmas remains receptive, and, as a consequence, stigmatic receptivity would limit the EPP. Stigmatic receptivity has been reported to be the limiting factor in kiwi (González, et al., 1995), apricot (Egea and Burgos, 1992) and cherry (Guerrero-Prieto et ael., 1985). It is worth noting that these results were obtained under experimental conditions with relative warm temperatures during flowering.

In apples and pears, ovule longevity has been identified as the limiting factor of the EPP so far (Cerovic and Ruzic, 1992; Le Lézec et al., 1997; Postweiler et al., 1985; Williams, 1965). However, there are not previous records on stigmatic receptivity restricting fruit set in these species. Again, temperature may play a part since these previous experiments were performed in cooler conditions. This observation could be a peculiarity of this cultivar, but alternatively, a similar behavior could occur in other pear cultivars grown in warmer latitudes. Thus, it has been shown in 'Doyene du Commice' pear that high controlled temperatures reduce EPP (Tromp and Borsboom, 1994) and this behavior could be due to a shortening of stigmatic receptivity. Thus, stigmatic receptivity could be an important factor limiting pear flower receptivity and hence cropping performance under warmer conditions.

\section{Literature Cited}

Atkinson, C.J. and L. Taylor. 1994. The influence of autumn temperature on flowering time and cropping of Pyrus communis cv. Conference. J. Hort. Sci. 69:1067-1075.

Beattie B.B. and R.R.W. Folley. 1977. Production variability in apples crops. Scientia Hort. 6:271-279.

Browning, G. and J. M. Miller. 1992. The association of year-to-year variation in the average yield of pear cv. Conference in England with weather variables. J. Hort. Sci. 67:593-599.

Cambra, M. and J. Herrero. 1978. Estudios sobre la irregularidad de producción de la variedad de peral "Agua de Aranjuez". An. Aula Dei 14:76-94.

Cerovic, R. and R. Ruzic. 1992. Senescence of ovules at different temperatures and their effect on the behavior of pollen tubes in sour cherry. Scientia Hort. 51:321-327.

Crisosto, C.H., P.B. Lombard, D.G. Richardson, and R. Tetley. 1992. Putrescine extends effective pollination period in 'Comice' pear (Pyrus communis L.) irrespective of post-anthesis ethylene levels. Scientia Hort. 49:211-221.

Egea, J. and L. Burgos. 1992. Effective pollination period as related to stigma receptivity in apricot. Scientia Hort. 52:77-83.

Ferree, D.C. and C.R. Rom. 1984. Quality apples come from strong spurs. Amer. Fruit Grower. May 1984, 25-26.

Free, J.B. 1964. Comparison of the importance of insect and wind pollination of apple trees. Nature 201:726-727.

González, M.V., M. Coque, and M. Herrero. 1995. Stigmatic receptivity limits the effective pollination period in kiwifruit. J. Amer. Soc. Hort. Sci. 120:199-202.

Guerrero-Prieto, V.M., M.D. Vasilakakis, and P.B. Lombard. 1985. Factors controlling fruit set of 'Napoleon' sweet cherry in western Oregon. HortScience 20:913-914.

Herrero, M. 1983. Factors affecting fruit set in 'Agua de Aranjuez' pear. Acta Hort. 139:91-96.

Jackson, J.H. and P.J.C. Hamer. 1980. The causes of year-to-year variation in the average yield of Cox's Orange Pippin apple in England. J. Hort. Sci. 55:149-156.

Jaumien, F. 1968. The cause of poor bearing trees of the variety 'Doyenne du Comice'. Acta Agrobotanica 21:75-106.
Jefferies, C.J. and A.R. Belcher. 1974. A fluorescent brightener used for pollen tube identification in vivo. Stain Technol. 49:199-202.

Johansen, D.A. 1940. Plant microtechnique. McGraw-Hill, New York. Le Lézec, M., P. Guérif, and A. Belouin. 1997. Doyenné du Comice comparée à Williams. Mieux comprendre la pollinisation d'une variété. L'arboriculture Fruitière 511:41-47.

Linskens, H.F. and K. Esser. 1957. Uber eine spezifische Anfärbung der Pollen-shläuche und die Zagl Kallosapropten nach selbstung und fremdung. Naturwiss 44:16.

Lombard, P.B., R.R. Williams, K.G. Stott, and C.J. Jeffries. 1972. Temperature effects on pollen tube growth in styles of Willians' pear with a note on pollination deficiencies of comice pear. Compte rendue du symposium 'Culture du Poirier' p. 265-279.

Modlibowska, I. 1945. Pollen tube growth and embryo-sac development in apples and pears. J. Pomol. 21:57-89.

Postweiler, K., R. Stösser, and S.F. Anvari. 1985. The effect of different temperatures on the viability of ovules in cherries. Scientia Hort. 25:235-239.

Sanzol J. 2001. Mecanismos reproductivos que regulan la fructificación en peral (Pyrus communis L.) cv. ‘Agua de Aranjuez'. PhD diss. Public Univ. Nav.

Sanzol J. and M. Herrero. 2001. The effective pollination period in fruit trees. Scientia Hort. 90: 1-17.

Sanzol J. and M. Herrero. 2002a. Identification of self-incompatibility alleles in pear (Pyrus communis L.) cultivars. Euphytica 128:325-331.

Sanzol J. and M. Herrero. (2002b. ) Fructificación en el cultivar de peral 'Agua de Aranjuez'. I Requerimientos de polinización. Fruticultura Profesional 130:25-32.

Sanzol J., P. Rallo, and M. Herrero. 2003a. Asynchronous development of stigmatic receptivity in the pear (Pyrus communis L. Rosaceae) flower. Amer. J. Bot. 90:78-84.

Sanzol J.,P. Rallo, and M. Herrero. 2003b. Fructificación en el cultivar de peral 'Agua de Aranjuez'. II Evaluación de polinizadores. Fruticultura Profesional, 131 (in press)

Sotes, V. 1975. Estudio del crecimiento del tubo polínico y de la longevidad de óvulos en la variedad de peral "Blanquilla de Aranjuez". ITEA 19:23-29.

Tabuenca, M.C. 1964. Necesidades de frío invernal de variedades de albaricoquero, melocotonero y peral. An. Aula Dei 7:113-132.

Thompson, M.M. and L.J. Liu. 1973. Temperature, fruit set, and embryo sac development in 'Italian' prune. J. Amer. Soc. Hort. Sci. 98 : 193-197.

Tromp, J. and O. Borsboom. 1994. The effect of autumn and spring temperature on fruit set and on the effective pollination period in apple and pear. Scientia Hort. 60:23-30.

Vasilakakis, M.D. and I.C. Porlingis. 1985. Effect of temperature on pollen germination, pollen tube growth, effective pollination period, and fruit set of pear. HortScience 20:733-735.

Watkins, R. 1976. Apple and pear, p. 147-250. In: N.W. Simmonds (eds.). Evolution of crop plants. Longman, London.

Williams, R.R. 1965. The effect of summer nitrogen applications on the quality of apple blossom. J. Hort. Sci. 40:31-41.

Williams, R.R. 1966. Pollination studies in fruit trees: II. The effective pollination period for some apple and pear varieties. Rpt. Long Ashton Res. Stat. 1965: 136-138.

Williams, R.R. 1970a. The effect of supplementary pollination in yield, p. 7-10. In: R.R. Williams and D. Wilson (eds.). Towards regulated cropping. Grower Books, London.

Williams, R.R. 1970b. Techniques used in fruit-set experiments, p. 57-61. In: R.R. Williams and D. Wilson (eds.). Towards regulated cropping. Grower Books, London.

Williams, R.R. 1970c. Factors affecting pollination in fruit trees, p. 193-207. In: L.C. Luckwill and C.V. Cutting (eds.). Physiology of the tree crop. Academic Press, London. 